\title{
Effect of Cassia occidentalis on Parthenium hysterophorus by way of secondary metabolites
}

Jai Knox

Environmental Sciences Research Laboratory, Department of Botany, Wilson College, Mumbai- 400 007, India.

Received: October 20, 2016; Revised: October 24 2016; Accepted: November 17, 2016

\begin{abstract}
Cassia occidentalis is an extensive growing weed in India with some medicinal value. It has been reported to show strong biochemical interaction causing inhibition of Parthenium bysterophorus which is an obnoxious weed of today. The present study was performed to confirm its inhibition on Parthenium. Biological parameters like Seed germination, Germination velocity index, shoot length and root length of 10 days old Parthenium seedlings was recorded. Fresh weight (FW), Dry weight (DW) and Relative water content $\%$ (RWC) was recorded after treating the mature Parthenium plant with various aqueous leaf leachates of Cassia occidentalis. Aqueous leaf leachates of Cassia occidentalis which were prepared in different concentrations showed significant inhibition in all biological parameters on Parthenium. This study gives a strong clue regarding the potential of suppressive effect of allelochemicals present in Cassia on Parthenium.
\end{abstract}

Key words: Allelopathy; Biochemical Interaction; Coffee weed; Femine weed; Pharmacognosy

\section{Introduction}

Parthenium bysterophorus L., an invasive exotic weed is an aggressive colonizer of degraded areas with poor ground cover and exposed soils such as fallow wastelands, roadsides and overgrazed pastures. The weed is highly allergenic causing respiratory problems, dermatitis and asthma. Abandoned cultivated land, open areas of villages and other roadside open patches have become a "Parthenium Bank" in and around natural vegetation and the weed has the potential to establish even in harsh environmental conditions with high yield of viable seeds and high regeneration capacity, invasion and subsequent establishment in all kinds of habitat. In India, it is noticed from the mid-fifties and is presumed to have accidentally introduced in Maharashtra. In India, this weed has spread fast all over covering wastelands, railway yards, marshy patches, unused cultivable lands, grasslands, roadsides, along the canals and other areas. Allelopathy refers to the beneficial or harmful effect of one plant on another plant, both crops and weed species from the release of biochemicals, known as allelochemicals from plant parts by leaching. The first observation that antagonistic competitor plants could replace $P$. hysterophorus, and therefore, had potential for biological control, appears to have been made by Singh, 1983 who noted that Cassia uniflora (Leguminosae) moved into areas previously occupied by Parthenium weed in the Maharashtra State of India. Research on the impact of other plants on Parthenium weed is limited. Therefore, keeping in view the present study was carried out to determine the cumulative effect of Cassia occidentalis on biological parameters of Parthenium and to assess the secondary metabolites of this plant on Parthenium bysterophorus.

\section{Materials and Methods}

Preparation of Aqueous Leachates: The upper part of shoot tips was collected from Cassia occidentalis. 100 grams of shoot tips were soaked in $500 \mathrm{ml}$ of double distilled water each under aseptic conditions for 10 days and placed in conical flasks in a refrigerator at $8 \pm 1^{\circ} \mathrm{C}$. The aqueous leachates were filtered through three layers of muslin cloth/cheese cloth to remove debris. The filtrate was then refiltered through one layer of Whatmann no. 1 filter paper. Leachates of $25 \%, 50 \%$ and $100 \%$ concentration were prepared with sterilized distilled water and used for bioassay.

Seed germination: Parthenium seeds were thoroughly washed with tap water to remove dirt and dust and rinsed with mild detergent solution for 5-7 minutes. The seeds were surface sterilized with $0.1 \% \mathrm{HgCl}_{2}$ for 10 minutes and again washed with sterilized distilled water for 4-7 times. Seeds were divided into three replicates of 10 seeds each. Seeds were placed on filter paper moistened with $25 \%$, $50 \%$ and $100 \%$ of shoot leachates. All the seed lots were allowed to germinate in $5^{\prime \prime}(12.7 \mathrm{~cm})$ petridishes. The relative humidity was $82 \pm 1^{\circ} \mathrm{C}$. Petridishes were covered and placed in sealed polythene bags to prevent further loss of volatile compound and kept undisturbed for 10 days at $25 \pm$

\footnotetext{
${ }^{*}$ Corresponding Author:

Dr. Jai Knox,

Environmental Sciences Research Laboratory,

Department of Botany, Wilson College,

Mumbai- 400 007, India.

E-mail: drjaiknox@gmail.com
}

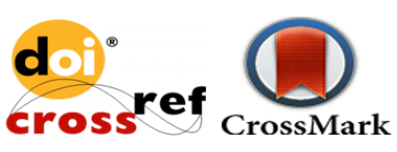


$2^{\circ} \mathrm{C}$. Control received distilled water. Germination percentage was calculated by the following formulaGermination percentage $=$ No. of seeds germinated/Total no. of seeds kept $\times 100$ and Germination velocity index (G.V.I) was calculated by the following formula of Babely, et al., (1986)Germination velocity index (G.V.I) $=$ No. of seeds germinated/No. of days

Seedling bioassay: Seedling of Parthenium were raised in plastic pots containing sterilized soil, sand and peat (1:1:1) and placed at room temperature 25 $\pm 1{ }^{\circ} \mathrm{C}$. These seedlings were sprayed with $25 \%, 50 \%$ and $100 \%$ concentration of aqueous shoot leachates of Cassia. Control received distilled water.

Determination of fresh weight, dry weight and relative water content: Viable Parthenium seeds were raised in earthen pots of diameter $10 \mathrm{~cm}$ containing sterilized soil. The plants were allowed to germinate till they reach at the height of $30 \mathrm{~cm}$. Then the aqueous leaf leachates of from Cassia occidentalis was sprayed upto one month at one week interval. The quantity of allelochemicals was $50 \mathrm{ml}$ at every spraying of $25 \%, 50 \%$ and $100 \%$ concentration. After one month of spraying the Parthenium plants were uprooted and first fresh weight was taken, then the dry weight was taken after placing the plants in oven for 24 hours at $74^{\circ} \mathrm{C}$ temperature. Deef and Abd El-Fattah (2008) equation was used to evaluate the relative water content as shown below:

$$
\mathrm{RWC} \%=(\mathrm{FW}-\mathrm{DW}) / \mathrm{FW} \times 100
$$

Statistical analysis: Statistical analysis of the data recorded was done. The design is Factorial Completely Randomized Design (FCRD) and conclusion was drawn from the data on the basis of Two Way Analysis of Variance technique. The software used is INDOSTAT; version 98. The calculated values were compared with tabulated value at $5 \%$ level of significance for the appropriate degree of freedom.

\section{Results}

The allelochemicals present in Cassia occidentalis showed a significant effect in all the biological parameters like Germination percentage, Germination velocity index (GVI), Shoot length, Root length, Fresh weight (FW), Dry weight (DW) and Relative water content \% (RWC) of Parthenium bysterophorus.

Germination percentage and GVI was significantly reduced when the aqueous shoot leachates of Cassia was treated on the viable seeds of Parthenium. Highest significant inhibition was recorded when the seeds of Parthenium (in triplicates) were treated with $100 \%$ aqueous shoot leachates of Cassia which was found to be only $10 \%$ (fig.1). GVI also showed minimum index in $100 \%$ aqueous shoot leachates and was found to be only 1 , followed by $50 \%$ in which $53.33 \%$ of germination was recorded. In $50 \%$ aqueous shoot leachates of Cassia 1.23 GVI was observed. Minimum inhibition was recorded in 25\% aqueous shoot leachates of Cassia in which $80 \%$ germination was recorded followed by GVI which was 2.83 (fig.1). Control received distilled water.

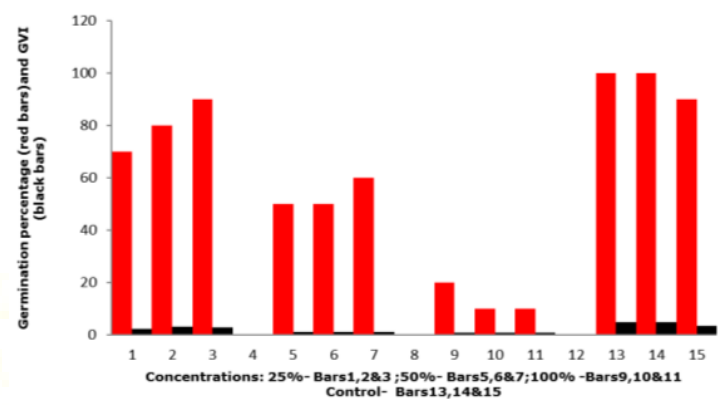

Figure 1: Effect of Cassia occidentalis on Germination percentage and Germination Velocity Index of Parthenium hysterophorus

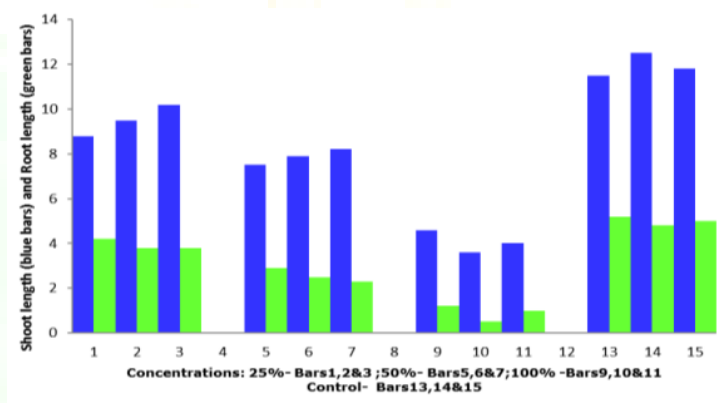

Figure 2: Effect of Cassia occidentalis on Seedling bioassay of Parthenium hysterophorus

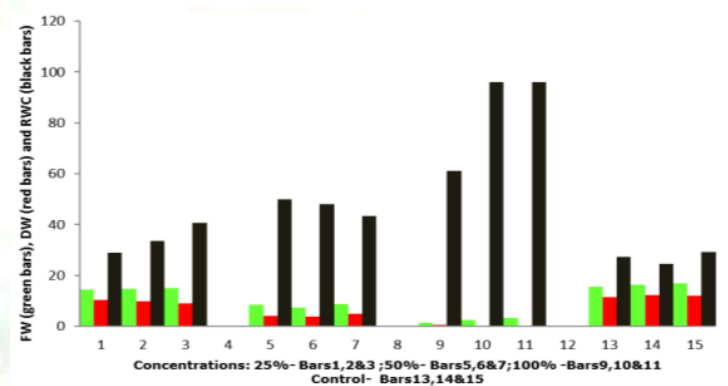

Figure 3: Effect of Cassia occidentalis on Fresh weight (FW), Dry weight (DW) and Relative water content $\%$ (RWC) of Parthenium hysterophorus

Cassia shoot leachates reduced the length of shoot and root of Parthenium seedlings. In fig-2. highest inhibition was recorded in $100 \%$ aqueous shoot leachates of Cassia i.e. 4.86 and 0.9 in the shoot and root length of Parthenium, followed by $50 \%$ in which 7.86 and 2.56 shoot and root length was recorded, respectively. Lowest inhibition was observed in $25 \%$ aqueous shoot leachates of Cassia in which 9.5 and 3.93 shoot and root length was observed, respectively. Control received distilled water. Fresh weight, Dry weight and Relative water content of Parthenium were highly reduced when $100 \%$ aqueous 
shoot leachates of Cassia were treated (fig-3). Highest inhibition was recorded in 100\% aqueous shoot leachates of Cassia in which 2.37, 0.26 and 84.36 FW, DW and RWC was recorded, respectively. In $50 \%$ aqueous shoot leachates of Cassia 8.26, 4.37 and $47.13 \mathrm{FW}$, DW and RWC was recorded followed by $25 \%$ in which $14.76,9.66$ and $34.4 \mathrm{FW}$, DW and RWC was recorded, respectively. Control received distilled water.

\section{Discussion}

The presence of inhibitory or allelopathic substances in aqueous leachates of $C$. occidentalis affects both the germination and growth of $P$. bysterophorus. There followed a spate of publications on the allelopathic effects and the potential of C. uniflora for biological control of Parthenium weed, in which phenolic leachates were identified (Joshi, 1991 a, b, c). From the reports, it appears that the wholesale propagation of $C$. uniflora was recommended for use in the biological control of Parthenium weed.

Leachates from a number of other plants have also been tested for their allelopathic effects on $P$. bysterophorus, including: Eucalyptus spp. (Theagarajan et.al., 1995); neem, mulberry and a wide range of woody plants of the Leguminosae (Acacia spp., Albizia lebbek, Cassia spp. \& Prosopis spp.) (Dhawan et.al., 1996). Most tested positive with significant inhibition of Parthenium weed at different growth stages, and have been considered as possible biological control agents. More recent work with marigold (Tagetes erecta; Heliantheae) at the National Research Centre for Weed Science (Jabalpur, Madhya Pradesh) has shown that in field trials, this plant can readily outcompete Parthenium bysterophorus in mixed stands, probably through allelopathy. Of the total flora studied different species exhibit different competitive abilities, amongst them Cassia occidentalis is the most promising species which can compete with Parthenium in natural environment (Knox et al., 2011).

\section{Conclusion}

During the course of this present study an effort has been made to assess the biochemical interaction of Parthenium. From the present experiments, it is clear that Cassia does compete with Parthenium through the mode of allelopathy. Cassia is considerably toxic to the growth and development of Parthenium. An extensive survey with regard to this has already been made at different sites. Thus, it provides eco-friendly and environmently safe approach to curb the menace of Parthenium hysterophorus.

\section{Acknowledgement}

I am thankful to Dr. V. J. Sirwaiya, Principal, Wilson College, Mumbai for his constant support and encouragement. I am also thankful to Mrs. Sandra Kavarana, HOD, Botany Department, Wilson College, Mumbai for providing necessary facilities.

\section{References}

1. Babely GS, Gautam SP, Kandya AK, Treatment of Albizzia lebbek Benth. Seeds to obtain better germination and vigour, Journal of Tropical Forest, 1986, 2, 105-113.

2. Deef HE, Abd El-Fattah RI, Allelopathic effects of water extracts of Artemisia princeps var. orientalis on wheat under two types of soils, Academic Journal of Plant Science, 2008, 1, 12-17.

3. Dhawan, SR, Gupta SK, Dhawan, P, Potential of leguminous plants in containing congress grass I: Effect of aqueous foliar leachates, Advances in Plant Sciences, 1996, 9, 151-154.

4. Joshi, S, Interference effects of Cassia uniflora Mill. on Parthenium hysterophorus L., Plant and Soil, 1991a, 132, 213-218.

5. Joshi, S. Biocontrol of Parthenium hysterophorus L. Crop Protection, 1991b, 10, 429-431.

6. Joshi, S. Biological control of Parthenium hysterophorus L. (Asteraceae) by Cassia uniflora Mill. (Leguminosae), in Bangalore, India. Tropical Pest Management, 1991c, 37, 182-184.

7. Knox, J, Jaggi, D, Paul, MS, Population Dynamics of Parthenium hysterophorus (Asteraceae) and its Biological suppression through Cassia occidentalis (Caesalpinaceae), 2011, 35, 111-119.

8. Singh, NP, Potential biological control of Parthenium hysterophorus L., Current Science, 1983, 52, 644.

9. Theagarajan, KS, Prabhu, VV, Sivaramakrishnan, VR, A note on control of Parthenium weed, Indian Forester, 1995, 121, 855-856.

Cite this article as:

Jai Knox. Effect of Cassia occidentalis on Parthenium bysterophorus by way of secondary metabolites. Annals of Plant Sciences 5.11 (2016): 1451-1453.

DOI: http://dx.doi.org/10.21746/aps.2016.11.001

Source of support: Nil. 